\title{
Perbandingan Efektivitas antara Gabapentin 600 mg dan Gabapentin 900 mg Kombinasi dengan Ketorolak 30 mg/8 Jam sebagai Analgesia Pascabedah pada Total Abdominal Histerektomi dengan Anestesi Umum
}

\author{
Mumya Camary Yacob, Mhd. Ihsan, Dadik Wahyu Wijaya \\ Departemen Anestesiologi dan Terapi Intensif \\ Fakultas Kedokteran Universitas Sumatera Utara/Rumah Sakit H. Adam Malik Medan
}

\begin{abstract}
Abstrak
Gabapentin berkembang untuk penanganan nyeri akut pascabedah. Tujuan penelitian adalah menilai efektivitas gabapentin $600 \mathrm{mg}$ dan $900 \mathrm{mg}$ per oral kombinasi ketorolak $30 \mathrm{mg} / 8$ jam intravena sebagai analgesia pascabedah pada total abdominal histerektomi dengan anestesi umum. Penelitian uji klinis acak tersamar ganda dilakukan di RSUP H. Adam Malik Medan, RSUD Dr. Pirngadi Kota Medan, RS. Haji Medan, dan RS. Putri Hijau selama bulan Oktober 2015-Januari 2016. Terdapat 30 subjek penelitian, usia 18-60 tahun, status fisik American Society of Anesthesiologists (ASA) I-II yang menjalani operasi total abdominal histerektomi dengan anestesi umum. Subjek dibagi menjadi 3, yaitu kelompok A mendapat plasebo, kelompok B mendapat gabapentin $600 \mathrm{mg}$, dan kelompok C mendapat gabapentin $900 \mathrm{mg}$ kombinasi ketorolak $30 \mathrm{mg} / 8$ jam. Uji Kruskal Wallis digunakan untuk menilai efektivitas skor visual analogue scale (VAS) pascabedah serta uji chi-kuadrat untuk menilai kebutuhan rescue analgetia petidin selama 24 jam pascabedah. Pada perbandingan nilai VAS antara gabapentin $600 \mathrm{mg}$ dan gabapentin $900 \mathrm{mg}$ kombinasi dengan ketorolak $30 \mathrm{mg} / 8$ jam tidak ditemukan perbedaan nilai yang signifikan antara kedua kelompok studi ( $>0$,05). Simpulan, efek gabapentin $600 \mathrm{mg}$ dengan gabapentin $900 \mathrm{mg}$ kombinasi ketorolak $30 \mathrm{mg} / 8$ jam sebagai analgesia pascabedah tidak berbeda efektivitasnya dalam mengurangi nilai VAS dan kebutuhan rescue analgetia petidin selama 24 jam pascabedah.
\end{abstract}

Kata kunci: Gabapentin, kebutuhan rescue analgetia, visual analogue scale

\section{Effectiveness of Gabapentin $600 \mathrm{mg}$ and $900 \mathrm{mg}$ Combined Ketorolak as Postoperative Analgesics for Hysterectomy under General Anesthesia}

\begin{abstract}
Gabapentin is developed recently to manage postoperative acute pain. The purpose of this study was to assess the efficacy of $600 \mathrm{mg}$ and $900 \mathrm{mg}$ oral gabapentin combined with $30 \mathrm{mg} / 8 \mathrm{hours}$ intravenous ketorolak as the postoperative analgesics for total abdominal hysterectomy under general anesthesiaon visual analogue scale (VAS) and the need of pethidin in 24 hours postoperatively. A double blind controlled trial was performed to 30 subjects in H. Adam Malik General Hospital Medan, Dr. Pirngadi Hospital Medan,Haji Hospital Medan,and Putri Hijau Hospital Medan. The study was performed during the period of October 2015 to January 2016. Patients were 18 to 60 years old with PS-ASA I-II who underwent total abdominal hysterectomy under general anesthesia. Subjects were divided into 3 groups.: Group A who received placebo, group B who received $600 \mathrm{mg}$ of gabapentin, and group C who received $900 \mathrm{mg}$ of gabapentin combined with $30 \mathrm{mg} / 8$ hours ketorolak. The efficacy was assessed with post operative visual analogue scale (VAS) using Kruskal Wallis test, and the need for rescue analgesics pethidin in 24 hours postoperatively using chisquare test. The VAS scores of the group that received $600 \mathrm{mg}$ gabapentin and the group that received $900 \mathrm{mg}$ gabapentin combined with $30 \mathrm{mg} /$ hour ketorolak were not significantly different ( $\mathrm{p}>0.05)$. In conclusion, the effects of $600 \mathrm{mg}$ gabapentin and $900 \mathrm{mg}$ gabapentin combined with $30 \mathrm{mg} / 8$ hours ketorolak as the postoperative analgesics for total abdominal hysterectomy under general anesthesia are not different in terms of decreasing VAS score and the need for rescue analgesia pethidine in 24 hours postoperatively
\end{abstract}

Key words: Gabapentin, the need of analgesia rescue, visual analogue score

Korespondensi: Mumya Camari Yacob, dr. Departemen Anestesiologi dan Terapi Intensif Fakultas Kedokteran Universitas Sumatera Utara/RSUP H. Adam Malik Medan, Jl. Bunga Lou No. 17 Medan Tuntungan Km. 12, Mobile 081363406869, Email dr.mumya@yahoo.com 


\section{Pendahuluan}

Konsep terbaru analgesia pascabedah adalah kombinasi beberapa jenis analgetik seperti opioid, obat anti-inflamasi nonsteroid (AINS), parasetamol, ketamin dosis rendah, dan juga pemberian anestetik lokal perioperatif. Obat-obat tersebut masing-masing memiliki keterbatasan sehingga terus dikembangkan penelitian untuk mendapatkan obat adjuvan yang mempunyai efek analgetik serta dapat meningkatkan kualitas analgesia opioid, mengurangi kebutuhan opioid, mencegah atau mengurangi toleransi opioid, mengurangi level kecemasan, serta mempunyai batas keamanan yang lebar. ${ }^{1-4}$

Gabapentin secara kimiawi larut dalam air, memiliki rasa pahit, struktur berbentuk kristal putih mirip gugus gamma aminobutyric acid atau GABA dengan cincin cyclohexane. Aksi yang paling penting gabapentin adalah ikatan subunit $\alpha_{2} \delta$ voltage dependentcalcium channels. Ikatan ini terjadi pada medula spinalis dengan densitas tinggi pada lamina superficial dorsal horn. Kerja gabapentin ini akan menghambat pelepasan neurotransmiter eksitatori dan juga dapat menurunkan availabilitas glutamat pada reseptor $N$-methyl-D-aspartate (NMDA). . $^{5-8}$

Dosis gabapentin yang direkomendasikan untuk penatalaksanaan nyeri akut adalah 300 sampai $1.200 \mathrm{mg}$ sebagai dosis tunggal, pada rentang dosis itu menunjukkan bahwa gabapentin efektif untuk pengelolaan nyeri akut dengan menurunkan nilai visual analog scale (VAS) dan dapat mengurangi kebutuhan analgetik pascaoperasi. Dosis obat maksimal yang dianjurkan tidak boleh melebihi 1.200 mg, hal ini karena potensi untuk timbul efek samping dapat menjadi lebih besar, dengan alasan tersebut maka pada penelitian akhirakhir ini dilakukan pemberian analgetik yang dikombinasikan dengan analgetik lain dengan harapan efektivitas obat masing-masing akan meningkat baik dalam hal penanganan nyeri maupun dalam hal menurunkan kejadian efek samping. ${ }^{5,9-11}$

Pemberian gabapentin dengan dosis lebih dari 600 mg menunjukkan penurunan absorbsi. Bioavailabilitas gabapentin akan berbanding terbalik dengan besar dosis yang diberikan. Semakin besar dosis yang diberikan maka bioavailabilitas akan semakin kecil. Dosis $>600$ mg tidak lagi menunjukkan hubungan antara besar dosis dan respons obat yang diberikan. Untuk meningkatkan efektivitas gabapentin dosis $600 \mathrm{mg}$ dibutuhkan kombinasi dengan obat analgesia yang berefek sinergis dalam meningkatkan efektivitas serta mengurangi angka kejadian efek samping.

Ketorolak merupakan obat analgesia pasca bedah yang sering digunakan dan merupakan golongan anti-inflamasinonsteroid(AINS)yang bekerja di perifer dengan cara menghambat pelepasan mediator sehingga aktivitas enzim siklooksigenase terhambat dan juga sintesis prostaglandin tidak terjadi. Namun, efektivitas terhadap penanganan nyeri lebih baik apabila dikombinasikan dengan obat analgetik lain dalam mengurangi jumlah pemberian rescue analgetia opioid. Besar dosis yang diberikan terhadap efek samping yang timbul memiliki hubungan paling sering diteliti untuk mencari dosis yang tepat guna menekan efek samping yang timbul. ${ }^{11-13}$

Tujuan penelitian ini adalah untuk menilai efektivitas gabapentin $600 \mathrm{mg}$ dan $900 \mathrm{mg}$ per oral kombinasi ketorolak $30 \mathrm{mg} / 8$ jam intravena sebagai analgesia pascabedah pada total abdominal histerektomi dengan anestesi umum.

\section{Subjek dan Metode}

Penelitian ini menggunakan metode uji klinis acak tersamar ganda, dilakukan di Rumah Sakit Umum Pusat H. Adam Malik Medan, RSUD Dr. Pirngadi Kota Medan, RS Haji Medan, dan RS. Putri Hijau Medan. Penelitian dilakukan pada bulan Oktober 2015-Januari 2016. Pemilihan subjek penelitian berdasarkan atas kriteria inklusi, yaitu usia 18-60 tahun, physical status American Society of Anesthesiologists 1-2, visual analog scale preoperasi $0-1$, dan berat badan ideal sesuai body mass index (18,5-24,9 kg). Kriteria eksklusi adalah pasien yang memiliki riwayat kontraindikasi terhadap obat-obat yang digunakan pada penelitian ini, pasien dengan gangguan fungsi ginjal, dan pasien dengan riwayat mengonsumsi gabapentinoid 
atau analgetik 24 jam sebelumnya. Pasien drop out dari penelitian apabila subjek tersebut menolak untuk berpartisipasi lebih lanjut, operasi yang memanjang sehingga dibutuhkan tambahan obat anestesi umum, dan terjadi kegawatdaruratan jalan napas, jantung, paru, serta otak yang mengancam jiwa.

Pengambilan sampel penelitian dilakukan menggunakan metode consecutive admission (sesuai dengan urutan kedatangan pasien) pada pasien yang telah memenuhi kriteria inklusi. Ukuran sampel dihitung menggunakan rumus uji hipotesis rata-rata dua populasi independen berdasarkan pada hasil penelitian sebelumnya. Setelah memperhitungkan kemungkinan putus uji, didapatkan subjek penelitian tiap kelompok adalah 10. Kelompok penelitian dibagi menjadi tiga kelompok, yaitu kelompok A yang diberikan plasebo, kelompok B diberikan gabapentin $600 \mathrm{mg}$ per oral, dan kelompok C yang diberikan gabapentin 900 mg per oral. Ketiga kelompok dikombinasi dengan ketorolak $30 \mathrm{mg} / 8$ jam intravena.

Setelah mendapatkan persetujuan Komite Etik Penelitian Kesehatan Fakultas Kedokteran Universitas Sumatera Utara/Rumah Sakit Haji Adam Malik Medan, subjek penelitian dijelaskan tentang tujuan, kegunaan, tata cara pelaksanaan penelitian, dan cara penilaian nyeri visual analog scale (VAS), diikuti dengan menandatangani surat persetujuan untuk ikut penelitian (informed consent).

Ketiga kelompok dipuasakan selama enam jam, dilakukan pemasangan jalur intravena dengan venocath no. 18G, diberi cairan infus Ringer laktat (RL) $2 \mathrm{~mL} / \mathrm{kgBB}$ sejak puasa. Pasien diberikan dua kapsul pada saat 1 sampai 2 jam sebelum operasi dan dijelaskan kembali penilaian nyeri memakai skala VAS. Kemudian, dinilai skala VAS awal dan pengukuran awal tekanan darah, frekuensi nadi, serta frekuensi napas. Pasien dibaringkan terlentang serta dipasang alat pemantau berupa monitor EKG, tensimeter, dan saturasi oksigen. Infus preload cairan Ringer laktat sebanyak $10 \mathrm{~mL} / \mathrm{kgBB}$ sebelum dilakukan tindakan induksi general anestesi. Hemodinamik satu menit sebelum intubasi diukur, kemudian laringoskopi direk menggunakan laringoskop dan trakea diintubasi menggunakan pipa endotrakea yang sesuai ukuran. Hemodinamik kembali diukur setelah dilakukan tindakan intubasi yaitu pada menit ke-1, 3, dan 5. Pembedahan dimulai, kemudian diberikan ketorolak $30 \mathrm{mg}$ i.v. pada saat 30 menit sebelum ekstubasi yang dilanjutkan setiap 8 jam. Selesai pembedahan, pasien dilakukan ekstubasi. Waktu ekstubasi dicatat dan dianggap sebagai nilai jam 0 (T0), apabila nilai VAS yang ditunjukkan oleh pasien menunjukkan tingkat nyeri sedang sampai berat (VAS >3) maka pasien diberikan analgetik tambahan, yaitu petidin $0,5 \mathrm{mg} /$ kgBB intravena. Dilakukan pencatatan dan pengamatan pada pasien terhadap tanda vital pada T-0 (jam ke-0), T-2 (jam ke-2), T-4 (jam ke4), T-8 (jam ke-8), T-12 (jam ke-12), dan T-24 (jam ke-24) setelah pasien diekstubasi. Dinilai skor VAS dan efek samping saat istirahat pada $\mathrm{T}-2$, T-4, T-8, T-12, dan T-24.

Jumlah sampel ditentukan dengan rumus perbedaan proporsi efektivitas dua tindakan dengan tingkat kepercayaan 95\% dan besar uji kekuatan adalah 90\%. Dari rumus tersebut didapatkan jumlah sampel 9 untuk tiap-tiap kelompok perlakuan, kemudian ditambah $10 \%$ kemungkinan pengeluaran sampel sehingga jumlah sampel tiap-tiap kelompok 10 orang sehingga jumlah semua sampel 30 orang. Data yang terkumpul diolah dan dianalisis secara statistika dengan Uji Kruskal Wallis untuk menilai efektivitas skor visual analogue scale (VAS) pascabedah serta uji chi-square untuk menilai kebutuhan rescue analgesia petidin selama 24 jam pascabedah memakai program statistical product and service solution (SPSS) 23,0 for windows. Nilai $\mathrm{p}<0,05$ dianggap signifikan atau bermakna secara statistik.

\section{Hasil}

Karakteristik antropometri, yaitu berat badan, tinggi badan, dan body mass index (BMI) ketiga kelompok tidak menunjukkan perbedaan ratarata yang signifikan ( $p>0,05$; Tabel 1 ) .

Pada pengamatan T-2 dan T-4 tampak bahwa nilai VAS rata-rata pada kelompok plasebo (A) lebih tinggi dibanding dengan kelompok gabapentin $600 \mathrm{mg}$ (B) dan gabapentin 900 
Tabel 1 Karakteristik Subjek Penelitian

\begin{tabular}{|c|c|c|c|c|}
\hline Karakteristik & $\begin{array}{c}\text { Kelompok A } \\
(n=10)\end{array}$ & $\begin{array}{c}\text { Kelompok B } \\
(n=10)\end{array}$ & $\begin{array}{c}\text { Kelompok C } \\
(n=10)\end{array}$ & $\mathbf{P}$ \\
\hline Usia, rata-rata $(\mathrm{SB})$, tahun & $39,7(9,24)$ & $44,4(9,56)$ & $48(7,32)$ & $0,169^{a}$ \\
\hline Berat badan, rata-rata (SB), kg & $52,65(4,92)$ & $51,8(4,34)$ & $52,5(4,93)$ & $0,460^{\mathrm{a}}$ \\
\hline Tinggi badan, rata-rata (SB), $m$ & $1,54(0,06)$ & $1,53(0,07)$ & $1,55(0,04)$ & $0,343^{\mathrm{a}}$ \\
\hline $\mathrm{BMI}$, rata-rata $(\mathrm{SB}), \mathrm{kg} / \mathrm{m}^{2}$ & $22,26(1,57)$ & $22,13(1,55)$ & $21,86(1,40)$ & $0,712^{\mathrm{a}}$ \\
\hline \multicolumn{5}{|l|}{ Pendidikan, $\mathrm{n}$} \\
\hline SD & 1 & 1 & 0 & \multirow[t]{4}{*}{$0,422^{\mathrm{b}}$} \\
\hline SMP & 0 & 2 & 0 & \\
\hline SMU & 8 & 4 & 7 & \\
\hline Perguruan Tinggi & 1 & 3 & 3 & \\
\hline \multicolumn{5}{|l|}{ Suku, n } \\
\hline Batak & 8 & 6 & 3 & \multirow[t]{3}{*}{$0,343^{\mathrm{b}}$} \\
\hline Jawa & 2 & 2 & 6 & \\
\hline Melayu & 0 & 2 & 1 & \\
\hline \multicolumn{5}{|l|}{ Pekerjaan, $\mathrm{n}$} \\
\hline IRT & 6 & 5 & 8 & \multirow[t]{9}{*}{$0,543^{\mathrm{b}}$} \\
\hline Mahasiswa & 1 & 0 & 0 & \\
\hline Pegawai magang & 1 & 0 & 0 & \\
\hline Pegawai swasta & 0 & 0 & 1 & \\
\hline Pekerja lepas & 1 & 0 & 0 & \\
\hline Petani & 1 & 1 & 0 & \\
\hline PNS & 0 & 1 & 1 & \\
\hline Tenaga honor & 0 & 1 & 0 & \\
\hline Wiraswasta & 0 & 2 & 0 & \\
\hline \multicolumn{5}{|l|}{ PS ASA, n } \\
\hline 1 & 10 & 7 & 8 & \multirow[t]{2}{*}{$0,245^{\mathrm{b}}$} \\
\hline 2 & 0 & 3 & 2 & \\
\hline $\begin{array}{l}\text { Jarak waktu pemberian obat } \\
\text { sebelum mulainya operasi, rata-rata } \\
\text { (SB), menit }\end{array}$ & $86,10(17,69)$ & $85,2(17,85)$ & $87,5(16,67)$ & $0,465^{a}$ \\
\hline Lama operasi, rata-rata (SB), menit & $141,2(32,86)$ & $139,5(27,58)$ & $141,5(36,67)$ & $0,424^{a}$ \\
\hline
\end{tabular}

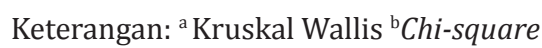

mg (C) dengan perbedaan yang bermakna secara statistika $(\mathrm{p}<0,05)$. Pada pengamatan T2 nilai VAS rata-rata pada kelompok A adalah 4, sedangkan pada kelompok B dan C adalah 1,8 dan 1,5 masing-masing. Begitu pula pada penagamatan T-4, nilai VAS rata-rata pada kelompok A adalah, 4 sedangkan pada kelompok B dan C adalah 2,3 dan 2,2 (Tabel 2).
Penilaian VAS kelompok studi B dan C dari pengamatan T-2-T-24. Berdasarkan penilaian VAS diketahui tidak terdapat perbedaan nilai VAS yang signifikan antara kelompok B dan C (Tabel 3).

Berdasarkan uji chi-kuadrat ditemukan perbedaan proporsi yang signifikan terhadap subjek yang mendapat rescue analgesia pada 
Tabel 2 Perbedaan VAS Setelah Operasi antara Kelompok A, B, dan C

\begin{tabular}{lcccc}
\hline \multicolumn{1}{c}{ VAS } & $\begin{array}{c}\text { Kelompok A } \\
(\mathbf{n = 1 0 )}\end{array}$ & $\begin{array}{c}\text { Kelompok B } \\
(\mathbf{n = 1 0})\end{array}$ & $\begin{array}{c}\text { Kelompok C } \\
(\mathbf{n = 1 0 )}\end{array}$ & $\mathbf{p}$ \\
\hline T-2, rata-rata (SB) & $3,4(1,43)$ & $1,8(0,42)$ & $1,5(0,53)$ & $<0,001^{\text {a }}$ \\
T-4, rata-rata (SB) & $4(2,06)$ & $2,3(0,68)$ & $2,2(0,63)$ & $0,045^{\text {a }}$ \\
T-8, rata-rata (SB) & $3,6(1,51)$ & $2,7(0,48)$ & $2,6(0,52)$ & $0,202^{\text {a }}$ \\
T-12, rata-rata (SB) & $2,9(0,74)$ & $2,9(0,74)$ & $2,8(0,79)$ & $0,930^{\text {a }}$ \\
T-24, rata-rata (SB) & $2,9(0,57)$ & $2,6(0,52)$ & $2,3(0,48)$ & $0,063^{\text {a }}$ \\
\hline
\end{tabular}

Keterangan: ${ }^{a}$ Kruskal Wallis

pengamatan $\mathrm{T}-2(\mathrm{p}=0,036), \mathrm{T}-4(\mathrm{p}=0,01)$, dan $\mathrm{T}-8(\mathrm{p}=0,036)$ A (plasebo) dengan kelompok B (gabapentin $600 \mathrm{mg}$ ) dan C (gabapentin 900 mg; Tabel 4).

\section{Pembahasan}

Dari data umum karakteristik sampel terlihat bahwa usia, berat badan, indeks massa tubuh, pekerjaan, suku, agama, dan status ASA antara ketiga kelompok studi tidak menunjukkan perbedaan yang signifikan secara statistika $(p>0,05)$. Demikian juga dengan data umum karakteristik lama mula pemberian obat dan lama pembedahan antara ketiga kelompok penelitian secara statistika tidak menunjukkan perbedaan signifikan $(p>0,05)$. Data sampel yang diperoleh dari ketiga kelompok studi relatif homogen sehingga layak dibandingkan dan dapat dipakai sebagai alat ukur untuk membandingkan efektivitas penanganan nyeri paskabedah.

Pada penelitian ini dilakukan pengukuran derajat nyeri memakai visual analogue scale
(VAS). Berdasarkan penilaian VAS diketahui terdapat perbedaan nilai VAS yang signifikan kelompok A dengan kelompok B dan C pada pengamatan $\mathrm{T}-2$ dan $\mathrm{T}-4 \quad(\mathrm{p}<0,05)$. Pada pengamatan selanjutnya tidak ditemukan nilai VAS yang signifikan pada ketiga kelompok studi ( $p>0,05)$, berdasarkan hasil uji statistik dapat disimpulkan bahwasanya gabapentin $600 \mathrm{mg}$ dan 900 mg kombinasi ketorolak memiliki efek analgetik pascabedah yang lebih baik daripada pemberian tunggal ketorolak untuk penanganan nyeri pascabedah. Berdasarkan uji statistik juga tidak terdapat perbedaan nilai VAS yang signifikan antara kelompok B dan C, hal ini membuktikan bahwa gabapentin 600 mg memiliki efektivitas analgesia pascabedah yang sama dengan gabapentin $900 \mathrm{mg}$ bila dikombinasikan dengan ketorolak. Hal ini merupakan tujuan multimodal analgesia.

Multimodal analgesia memakai 2 atau lebih obat analgesik yang memiliki mekanisme kerja yang berbeda untuk mencapai efek analgesik maksimal, pada penelitian ini yang menjadi pilihan adalah gabapentin dan non-steroid anti

Tabel 3 Perbedaan VAS Setelah Operasi antara Kelompok B dan C

\begin{tabular}{llll}
\multicolumn{1}{c}{ VAS } & \multicolumn{1}{c}{$\begin{array}{c}\text { Kelompok B } \\
\mathbf{( n = 1 0 )}\end{array}$} & $\begin{array}{c}\text { Kelompok C } \\
\mathbf{( n = 1 0 )}\end{array}$ & p \\
\hline T-2, rata-rata (SB) & $1,8(0,42)$ & $1,5(0,53)$ & $0,280^{\mathrm{a}}$ \\
T-4, rata-rata (SB) & $2,3(0,68)$ & $2,2(0,63)$ & $0,739^{\mathrm{a}}$ \\
T-8, rata-rata (SB) & $2,7(0,48)$ & $2,6(0,52)$ & $0,739^{\mathrm{a}}$ \\
T-12, rata-rata (SB) & $2,9(0,74)$ & $2,8(0,79)$ & $0,796^{\mathrm{a}}$ \\
T-24, rata-rata (SB) & $2,6(0,52)$ & $2,3(0,48)$ & $0,280^{\mathrm{a}}$ \\
\hline
\end{tabular}

Keterangan: a Mann-Whitney U 
Tabel 4 Pemberian Rescue Analgesia Setelah Operasi

\begin{tabular}{lcccc}
\hline Rescue Analgesia & $\begin{array}{c}\text { Kelompok A } \\
(\mathbf{n = 1 0 )}\end{array}$ & $\begin{array}{c}\text { Kelompok B } \\
(\mathbf{n}=\mathbf{1 0})\end{array}$ & $\begin{array}{c}\text { Kelompok C } \\
(\mathbf{n = 1 0})\end{array}$ & $\mathbf{p}$ \\
\hline T-2 & 3 & & & \\
Ya & 7 & 0 & 0 & $0,036^{\mathrm{a}}$ \\
Tidak & & 10 & 10 & \\
T-4 & 4 & & & \\
Ya & 6 & 0 & 0 & $0,01^{\mathrm{a}}$ \\
Tidak & & 10 & 10 & \\
T-8, n (\%) & 3 & & & \\
Ya & 7 & 0 & 0 & $0,036^{\mathrm{a}}$ \\
Tidak & & 10 & 10 & \\
T-12 & 2 & 2 & 2 & $1,000^{\mathrm{a}}$ \\
Ya & 8 & 8 & 8 & \\
Tidak & & & & \\
T-24, n (\%) & 1 & 0 & 0 & \\
Ya & 9 & 10 & 10 & \\
Tidak & & & & \\
\hline
\end{tabular}

Keterangan: ${ }^{a}$ Chi-square

inflamation drugs (NSAID), yaitu ketorolak sebagai kombinasi untuk menurunkan tingkat intensitas nyeri pada pasien yang mengalami nyeri pascabedah tingkat sedang sampai berat. Pemberian tunggal ketorolak hanya mampu mengatasi nyeri ringan sampai dengan nyeri sedang. Multimodal analgesia selain harus diberikan secepatnya atau disebut juga early analgesia, multimodal analgesia juga harus disertai dengan inforced mobilization (early ambulation) dan pemberian nutrisi secara oral secepatnya (early alimentation).

Penilaian efektivitas pemberian analgetik terhadap derajat nyeri sebaiknya disertai dengan penilaian kebutuhan analgesik untuk menilai kemampuan obat dalam memberikan analgesia yang adekuat selama kurun waktu tertentu. Waktu pemberian rescue analgetic berhubungan dengan efektivitas pre-emtif analgesia dan waktu paruh gabapentin serta ketorolak dalam memperpanjang jarak waktu pemberian obat rescue analgetic sehingga efek analgesik akan menurun bila melewati masa kerja obat dalam upaya mempertahankan nilai VAS $<4$. Berdasarkan pemberian rescue analgesia diketahui bahwa pada kelompok yang menerima plasebo telah diberikan rescue analgesia sejak pengamatan T-2-T-24. Ditemukan perbedaan proporsi yang signifikan pada jumlah subjek yang mendapatkan rescue analgesia pada pengamatan $\mathrm{T}-2(\mathrm{p}=0,036)$, $\mathrm{T}-4(\mathrm{p}=0,01)$, dan T-8 $(\mathrm{p}=0,036)$ kelompok A (plasebo) dengan kelompok B (gabapentin $600 \mathrm{mg}$ ) dan C (gabapentin $900 \mathrm{mg}$ ). Hal ini semakin menegaskan bahwa efektivitas multimodal analgesiagabapentin dan ketorolak dalam hal pemberian rescue analgesia lebih baik dibandingkan dengan pemberian tunggal. Sementara itu, pada kelompok subjek yang mendapatkan gabapentin $600 \mathrm{mg}$ dan 900 mg baru mendapatkan rescue analgesia pada pengamatan T-12 dengan jumlah subjek yang sama, yaitu dua orang yang menandakan tidak ada perbedaan yang signifikan pemberian rescue analgesia antara gabapentin $600 \mathrm{mg}$ dan 900 mg. Hasil ini menunjukkan bahwa gabapentin dosis $600 \mathrm{mg}$ kombinasi ketorolak dapat mengimbangi gabapentin $900 \mathrm{mg}$ dalam pemberian rescue analgesia. Keadaan tersebut menggambarkan keuntungan metode 
multimodal analgesia yang dapat menurunkan dosis kebutuhan gabapentin, namun memiliki efektivitas yang sama apabila dikombinasikan dengan ketorolak dalam hal pemberian rescue analgesia.

\section{Simpulan}

Tidak dijumpai perbedaan efektivitas analgesia pascabedah pada pemberian gabapentin 600 mg per oral kombinasi dengan ketorolak 30 $\mathrm{mg} / 8$ jam intravena dengan gabapentin 900 mg per oral kombinasi dengan ketorolak $30 \mathrm{mg} / 8$ jam intravena sebagai analgesia pascabedah.

\section{Daftar Pustaka}

1. Morgan GE, Mikhail MS, Murray MJ, penyunting. Clinical anesthesiology. Edisi ke-5. New York: Lange Medical Books/ McGraw-Hill; 2013.

2. Khahi MP, Yaghooti AA, Marashi SH, Nadjafi A. Effect of preemptive gabapentin on post operative pain following lower extremity orthopedic surgery under spinal anesthesia. Singapore Med. 2011;52(12):879-82.

3. Shrestha GS, Marhatta MN, Amatya R. Use of gabapentin, esmolol, or their combination to attenuate haemodynamic response to laryngoscopy and intubation. Kathmandu University Med J. 2011;9:1-4.

4. Tiipana EM. From improved management of acute pain to prevention of persistent post operative pain. Helsinki: Helsinki University Print; 2013.

5. Parikh HG, Dash SK, Upasani CB. Study of the effect of oral gabapentin used as preemptive analgesia to attenuate post operative pain in patients under general anesthesia. Saudi J Anesth. 2010;4(3):13741.

6. Mardani-Kivi M, Mobarakeh MK, Keyhani S, Motlagh KH, Ekhtiari KHS. Is gabapentin effective on pain management after arthroscopic anterior cruciate ligament reconstruction? a triple blinded randomized controlled trial. Arch Bone Joint Surg. 2013;1(1):18-22.

7. Jadeja CA, Jadaliwala R, Kathiria M. Preemptive use of gabapentin for post operative pain relief in upper abdominal surgeries. Indian J Pain. 2014;28(2):99104.

8. Tiippana EM, Hamunen KH, Kontinen VK, Kalso EK. Do surgical patients benefit from perioperative gabapentin/pregabalin? A systematic review of efficacy and safety. Anesth Analg. 2007;104(6):1545-56.

9. Rawal N, Fischer HBJ, Ivani G, Narchi P, Stienstra R, Wulf H, dkk. Post operative pain management-good clinical practice. European Society Regional Anesthesia. Sweden. 2008;1(1):16-28.

10. Fabregat-Cid G, Asensio-Samper JM, Villanueva-Perez V, Lopez-Alarcon MD, De Andres-Ibanez J. Postoperative pain management for patients who are long term users of opioid. Rev Esp Anestesiol Reanim. 2011;58(1):25-33.

11. Zulfariansyah A, Nawawi AM, Bisri T. Perbandingan gabapentin $600 \mathrm{mg}$ dengan $1.200 \mathrm{mg}$ per oral preoperatifterhadap nilai visual analogue scale dan pengurangan kebutuhan petidin pascabedah pada modifikasi mastektomi radikal. J Anestesi Perioperatif. 2013;1(3):174-82.

12. Prayogi K. Perbandingan visual analogue scale dan efek samping dari gabapentin $900 \mathrm{mg}$ dengan gabapentin $1.200 \mathrm{mg}$ per oral sebagai preemptif analgesia pascabedah dengan spinal anestesi. Medan: Departemen Anestesiologi dan Terapi Intensif FK USU/RSUP H. Adam Malik Medan; 2015.

13. Parsa AA, Sprouse-Blum AS, Jackowe DJ, Lee M, Oyama J, Parsa FD. combined preoperative use of celecoxib and gabapentin in the management of postoperative pain. Anesth Plast Surg. 2009;33:98-103. 